\title{
Needs of Head and Neck Cancer Patients and Stakeholders During Rehabilitation
}

\author{
Maria Karampela* \\ makar@itu.dk \\ IT University of Copenhagen \\ Copenhagen, Denmark
}

\author{
Talya Porat \\ t.porat@imperial.ac.uk \\ Imperial College London \\ London, UK
}

\author{
Vasiliki Mylonopoulou \\ vasiliki.mylo@oulu.fi \\ University of Oulu \\ Oulu, Finland
}

\begin{abstract}
The foreseen growth of Head and Neck cancer (HNC) incidents will require future rehabilitation services to meet the needs of a wider population. This study reports the empirical findings of a case study conducted at a cancer rehabilitation center in Copenhagen, aiming to elicit the needs of HNC patients, informal caregivers and healthcare professionals (HCPs). Our results point out that patients and stakeholders' needs are interrelated, as they faced common challenges pertinent to provision and distribution of information. This study, though preliminary, underlines the importance of inclusion of all actors in the design of future interventions.
\end{abstract}

\section{CCS CONCEPTS}

- Information systems $\rightarrow$ Information systems applications;

\section{KEYWORDS}

Rehabilitation needs, patients, informal caregivers, healthcare professionals, cancer rehabilitation, head and neck cancer

\section{ACM Reference format:}

Maria Karampela, Talya Porat, and Vasiliki Mylonopoulou. 2019. Needs of Head and Neck Cancer Patients and Stakeholders During Rehabilitation. In Proceedings of The 13th International Conference on Pervasive Computing Technologies for Healthcare, Trento, Italy, May 20-23, 2019 (PervasiveHealth'19), 7 pages.

https://doi.org/10.1145/3329189.3329236

\section{BACKGROUND}

Globally, Head and Neck cancer (HNC) results in more than 550,000 new cases and 380,000 deaths annually [25], and the number of cases is rising [14]. In Europe, there were approximately 250,000 cases and 63,500 deaths in 2012 [27]. Primary risk factors leading to the development of HNC include tobacco use, alcohol consumption, human papillomavirus infection, and Epstein-Barr virus infection [25], while the most common types of HNC are in pharynx, larynx and oral cavity [55]. HNC rehabilitation is accompanied with high morbidity compromising vital functions, such as swallowing, respiration and speech. These functions are directly related to the quality

Permission to make digital or hard copies of all or part of this work for personal or classroom use is granted without fee provided that copies are not made or distributed for profit or commercial advantage and that copies bear this notice and the full citation on the first page. Copyrights for components of this work owned by others than ACM must be honored. Abstracting with credit is permitted. To copy otherwise, or republish, to post on servers or to redistribute to lists, requires prior specific permission and/or a fee. Request permissions from permissions@acm.org.

PervasiveHealth'19, May 20-23, 2019, Trento, Italy

(C) 2019 Association for Computing Machinery.

ACM ISBN 978-1-4503-6126-2/19/05 .. \$15.00

https://doi.org/10.1145/3329189.3329236 of patients' life making often treatment decisions challenging [19]. Quality of life has been defined initially by the WHO "as complete physical, mental and social welfare state and not only the absence of the disease" [13].

Survivors of HNC often face long-term side-effects that have an impact on their quality of life. Dysphagia is the most common longterm physical side-effect of chemoradiotherapy treatment and can be defined as the difficulty of moving food through the mouth to the back of the tongue, and difficulty with swallowing and movement of food through the 'throat' or pharynx [29]. Swallowing disability is a priority issue for patients [69] and is associated with higher risk of poorer oral intake, as well as fundamental changes to social activities and consequently poorer quality of life [51,63]. Previous studies point out that HNC patients can face eating problems 18 months after the end of radiation therapy [57]. Apart from physical side-effects, patients often experience psychological challenges. Adjustment disorders, major depression and fear of cancer recurrence are among the main psychological issues that newly diagnosed patients encounter [44, 62].

HNC has also implications on the patient's family and friends. Patients' relatives and friends, also known as informal or family caregivers, usually provide support to patients during the treatment and post-treatment periods [48]. Caregiving during cancer can be a difficult and stressful assignment. According to previous studies, informal caregivers of HNC may experience even higher levels of anxiety than patients, which can be related among others to the fear of cancer recurrence [48]. The importance of the mental and emotional wellbeing of relatives during the care-giving phase, has led to suggestions for specialized psychosocial interventions to support them. These interventions have been seen as an effective approach to alleviate informal caregivers' psychosocial burden, while also having positive impact on the quality of patients' lives [8]

Treatment decisions in HNC are critical and require the establishment of a multidisciplinary team of healthcare professionals (HCPs). A multidisciplinary team can consist of surgeons, radiologists, pathologists, oncologists, dentists, as well as nurses, and speech/swallow therapists $[9,17]$. The establishment of such a team is currently the suggested approach for decision-making pertinent to treatment and rehabilitation interventions in HNC cancer incidents [32]. Despite the fact that HNC patients have multiple and severe unmet needs compared to other cancer types [37] and that rehabilitation has a significant role in addressing those needs $[22,42,60]$ rehabilitation is not always part of the clinical practice in HNC care [49].

Comprehension of patients' needs during cancer rehabilitation treatment is challenging, but also essential for the development of 
holistic rehabilitation services and patient-centered technologies [39]. Advances in technology have the potential to address some of the patients', informal caregivers' and HCPs' needs. These technologies can exploit the benefits of pervasive computing, wearable sensors, mobile technologies, big data analytics and health information systems to promote wellbeing [40], including management of treatment information, remote monitoring and communication with HCPs and peers.

The interrelated needs of HNC patients, caregivers and HCPs during $\mathrm{HNC}$ rehabilitation has been the subject of previous studies. The study of McEwen et al. [49], utilized focus groups to address the needs of patients and stakeholders, while providing insights pertinent to facilitators and barriers to recuperate functional health In the same vein, Ringash et al. investigated the physical, emotional and cognitive needs of HNC patients and stakeholders, suggesting directions for future interventions [61]. Finally, a review of previous literature presented an overview of relevant studies, concluding that there is a need for further investigation related to the informational and support needs of patients and caregivers [24]. This study reflects upon the study of [24] by exploring the needs of HNC patients and stakeholders during HNC rehabilitation. The present study addresses the following research question: What are the needs of the different stakeholders from a rehabilitation service in HNC treatment? This paper presents a case study that was conducted at the Center For Kraeft \& Sundhed Kobenhavn (CKSK), during a service design course for a masters degree. CKSK is the largest and newest rehabilitation center in Denmark and of fers rehabilitation services to approximately 1,500 cancer survivors every year.

The remainder of the paper is organized as follows: The Methods section outlines the data collection and analysis methods. The Findings section reports the stakeholders' needs, while the Discussion section discusses the needs and conclusions of the study.

\section{METHODS}

\section{Case study in CKSK rehabilitation center}

According to Yin, case study is an empirical inquiry that explores a contemporary phenomenon within its real life context utilizing multiple sources of evidence in order to understand and explore the phenomenon under investigation [70]. This case study was conducted by MSc students during a Service Design course offered by IT-University of Copenhagen in the second semester of 2017, to elicit requirements from different stakeholders, including patients, HCPs, informal carers and relatives. Their final aim was to propose digital solutions that could support head and neck cancer (HNC) patients and stakeholders during rehabilitation process. To achieve that the students collaborated with two case partners Sundhed.dk and CKSK. Sundhed.dk is a national and publicly funded health data and information portal in Denmark and CKSK is a cancer rehabilitation center in Copenhagen. The present study utilizes data collected only from CKSK.

The Danish healthcare system is funded by taxes and offers services free of charge to all the residents of the country. Danish residents have access to general practitioners (GPs), specialists and hospital services and patients' contribution to healthcare expenses is mainly for the purchase of medicines, the dental care of adults and physiotherapy treatments [58]. The healthcare system has decentralized administration and is distributed in 5 districts and 98 municipalities. The hospitals apart from emergency treatments provide also rehabilitation services to patients with cancer, while municipalities play a key role in the prevention of the disease [2, 58].

Rehabilitation of cancer patients in Denmark includes a wide range of interventions, such as physical therapy, psychosocial support and physical training $[6,23,50]$. While, WHO provides a broader definition of rehabilitation [7], in a Danish context the definition states explicitly that rehabilitation involves apart from the patients and HCPS, also patients' relatives. In addition, it highlights the active participation of patients in decision-making "Rehabilitation takes into account of the person's situation as a whole and the decisions he or she must make" [1]. In the Danish healthcare system, the national guidelines for cancer treatment indicate that rehabilitation interventions should lead to the fastest possible onset of treatment, with a long-term strategic objective to increase the survival rates of cancer patients [5].

Rehabilitation programmes for cancer patients in Danish municipalities are available since 2007. Municipalities are only responsible for the generalised rehabilitation interventions [15, 66], while the hospitals hold the main responsibility for specialized rehabilitation services for patients with cancer [5]. Apart from the municipalities and hospitals, private cancer organizations [3] and the Danish Cancer Society also offers rehabilitation services to patients [4].

From the view point of case partners of the present study the collaboration with students reflected upon a need. Only few municipalities in Danish district offer a rehabilitation programme for HNC patients, therefore CKSK center has to share professional expertise and knowledge with other municipalities that lack rehabilitation experience. This problem has inspired CKSK and the Danish national health information portal Sundhed.dk to collaborate in order to create a service that can overcome this problem and share rehabilitation expertise and knowledge to other parts of Denmark. Before initiating the project, the case partners wanted to explore and fully comprehend the needs of the stakeholders to develop an agile service.

\section{Participants' characteristics}

A group of four HNC patients during their rehabilitation and four informal caregivers were recruited from CKSK. A female and three male patients, age range between 34 - 74 years old, on their first year of rehabilitation were chosen to be included, as that is the phase they have frequent interactions with the rehabilitation service. Patients with severe challenges in communication were excluded from the study. Inclusion/exclusion decision was made by the HCPs of the rehabilitation center. Empirical data have been also collected from HCPs such as specialized doctors, nurses and nutritionists. Table 1. presents participants' characteristics.

\section{Data collection}

The data collected for this study is based on the exam reports submitted by the students. Before the case study both the patients and stakeholders were informed about the purpose of the study and signed a consent form. The twenty four students that participated in the course were divided to five groups. After an initial brief 
Table 1: Participants' characteristics

\begin{tabular}{lllll}
\hline Participant & Gender & Age & Rehab. time & Role $^{2}$ \\
\hline Patient 1\# & M & 74 & 9 & - \\
Patient 2\# & M & 67 & 12 & - \\
Patient 3\# & M & 34 & 3 & - \\
Patient 4\# & F & 56 & 10 & - \\
\hline Inf. caregiver 1\# & F & - & - & Husband \\
Inf. caregiver 2\# & F & - & - & Husband \\
Inf. caregiver 3\# & M & - & - & Father \\
Inf. caregiver 4\# & F & - & - & Husband \\
\hline \multicolumn{5}{c}{ Time in months, ${ }^{2}$ Informal caregiver's role }
\end{tabular}

meeting with HCPs that were working at CKSK, students met with cancer patients, their relatives and healthcare professionals in order to collect the empirical data.

The students carried out semi-structured interviews and fieldwork to obtain information about the needs and expectations of patients, informal caregivers, HCPs and the case partners. Participants were instructed to express their personal experiences during their rehabilitation and were encouraged to comment about the content of questions, if they felt they were too personal or made them feel uncomfortable. The interviews were unraveled around the service provided in the following six areas: food and nutrition, oral exercises, the role of the relatives, dental hygiene and dentists, intimacy and physical activities. Students reported that the semi-structured interviews facilitated an open dialogue in which the respondents could better influence the conversation, embracing the theory that knowledge evolves through dialogue $[45,46]$.

In the premises of CKSK, HCPs such as occupational therapists, physiotherapists, nurses and social workers, gave short presentations to students describing their work practices and relationships to patients, as well as their specific needs in regards to their occupation. By identifying the different stakeholders and the interplay between them, the students were able to characterize their roles and values pertinent to the rehabilitation process [65].

In addition to interviews, several students performed a desk research, which includes reviewing previous literature to collect information about the relevant stakeholders and to acquire some technical and medical understanding concerning patients with HNC. The majority of the students argued that desk research empowered them to gain a fundamental understanding of the existing research about rehabilitation of HNC patients and stakeholders in Denmark [54].

\section{Data analysis}

Thematic analysis was used to identify themes and sub-themes based on the empirical data that students reported [10]. All the four authors familiarized themselves with the reports by reading and reviewing them. Analytical notes were taken during this process. The authors adopted a collaborative process to analyze the findings, which was performed in two phases. Initially, the first two authors read the reports to identify themes and sub-themes. The authors had two face-to-face sessions in which the findings were discussed and themes and sub-themes were further defined. In the second phase, the third and fourth authors were involved in the data analysis process. After a briefing on initial themes and sub-themes by the first author, all the authors had an additional session, where a discussion on the themes took place and the data were grouped into the final themes.

\section{RESULTS}

The findings are presented as follows: (1) HNC patients' needs, (2) Informal caregivers' needs and (3) HCPs' needs.

\section{HNC patients' needs}

Patients' needs differ from individual to individual. Challenges pertinent to service delivery limitations such as lack of information and organizational challenges were reported by the patients. More specifically, they addressed lack of information at hospitals concerning the rehabilitation services provided by the municipalities.

An indication of considerable dissatisfaction for patients was related to unanswered questions. They felt that they do not have the opportunity to receive answers to questions that may suddenly arise:

"I had a lot of questions which I didn't feel got answered. I had to do my own experiences."

"The pamphlets were there, but you can't ask questions to a pamphlet!"

The findings highlighted issues arising from the service provision. Patients were dissatisfied receiving materials concerning their rehabilitation process mostly on paper:

"Yes, they could come up with something better. Something people can see on a screen, you know? That would help me, definitely."

"I don't want to write back and forth, and I don't want to read 400 pages of paper from this place. (rehabilitation center)"

Another point of contention was pertinent to information management. It was hard for them to keep track of all the information and translate it to relevant knowledge, especially during the period of cancer diagnosis:

"[...] it is insanely hard before the treatment period to understand what is going to happen. So, really really hard. Hmm, and there was very much information overload."

The experience of another patient concerning the management of medical information during the diagnosis period was the following:

"I could not tell them [the parents] anything because I did not have the information. I was totally far away when I was given the information."

These findings indicate how important it is for patients to receive information in a comprehensive way in order to have an overview of their cancer treatment and rehabilitation process. The majority of the patients found it demanding to manage and keep control of 
their tight treatment schedule:

"If you look at my calendar from April to August, I have something I need to do every day. Treatments for side-effects of cancer. You're in a hurry if you want to get well!"

\section{Informal caregivers' needs}

The needs of relatives and close friends, also known as informal caregivers of HNC patients were pertinent to practical aspects of everyday life. In terms of practical information, the informal caregivers argued that there were times they felt that they missed the knowledge of how to accommodate the patients' needs in order to establish a supportive relationship during the rehabilitation process. In addition, they experienced distress due to lack of information about the available rehabilitation options at hospital, as well as during the rehabilitation process. For example, one of the common side-effects of the radiation therapy is tooth decay, nevertheless, they argued that they were not aware that dental treatment is not part of the rehabilitation process.

\section{Healthcare professionals' needs}

HCPs' needs were also acknowledged, as their input was considered valuable in having a holistic overview of the service. The findings represent different HCP's specialties relevant to HNC rehabilitation and were focused on service-related needs.

HCPs' who were located in the capital city stated that they lack contextual knowledge, experience and information pertinent to HNC:

"In other municipalities they need concrete knowledge about what to do with this type of patients [...] because they don't have the same opportunities."

The majority of HCPs in the municipal level did not have previous experience and knowledge in treating HNC patients, pointing out that $\mathrm{HNC}$ rehabilitation requires specialized interventions. A desire for reliable information among HCPs was identified and highlighted the value of interventions which are reliable, trustworthy and accurate. In some cases, HCPs from Municipalities in Jutland had to arrange phone consultations with CKSK to find answers to their questions:

"How do we train the musculature?", "What kind of exercises should the physiotherapist use?", "What should the occupational therapist do?", "How do we teach them to sink and swallow?", "What kind of diet is necessary?"

HCPs agreed that digital solutions for knowledge sharing could have a positive impact on their performance. As medical professionals work with patients with serious health conditions, they wanted to ensure that the services they would provide will rely upon accurate and up-to-date information. When HCPs sought knowledge the main source of information was their colleagues. If their colleagues were not available, then they would seek knowledge through Sundhed.dk, Promedicin.dk or other sources of information. In the same vein, the value of knowledge and experience sharing between patients highlighted by HCPs as a means that would facilitate their work. However, HCPs mentioned that it is challenging to convince patients to gather and share their experiences in a formal setting. A clinical dietitian from the CKSK emphasized this problem directly:

"It is often very valuable when patients are able to share their experiences, but we find it challenging to get the patients together."

While knowledge sharing is a common practice in the secondary sector, HCPs highlighted that knowledge sharing practices are not common in the primary sector:

"In the secondary sector we shared a lot of data, insights and discussed a lot across different departments. In the primary care there is no such thing as knowledge sharing or discussion."

Another finding indicates that vital treatments such as dental treatment, and rehabilitation responsibilities are allocated at various authorities on different governmental levels. An employee from a municipality in Jutland said:

"This [the dentists] we have nothing to do with. So, I believe that it is the responsibility of the hospital. We have nothing to do with that."

This impedes the already decentralised municipal rehabilitation offer even more because of the uncertainty of distribution of responsibilities.

\section{DISCUSSION}

The aim of the present study was to elicit the needs of stakeholders during the rehabilitation of HNC patients in a Danish context. Our findings suggest that HNC patients, informal caregivers and HCPs have interrelated needs during rehabilitation.

Joint service-related challenges have been addressed by the patients and stakeholders during their rehabilitation. Service-related challenges concern unmet needs from the perspectives of patients and informal caregivers contextual to lack and organization of information. We have identified a relationship between the lack and organization of information, and the paper format and volume of the provided data. The provision of data in hard copies, such as pamphlets, has been seen by previous research as a factor that can lower the usability and the perceived value of data [33]. Digital interactive interventions and tailor-made communication have been proposed as effective approaches to provide information and answers to cancer patients and informal caregivers [11, 20, 21, 68]. A recent multi-institutional study concluded that HNC patients prefer multiple modes of information delivery (72\%), with one-to-one consultation being the most preferred method for cancer education followed by internet-based interventions [38]. Our findings are also in line with a national study concerning cancer rehabilitation in Denmark, which concluded that there is a need for more well-validated documentation based on patient needs [43].

Cancer patients have specific information requirements, often requesting to receive all the available information related to their cancer and its treatment $[18,53]$. In general, information about 
diagnostic tests and treatment options have been reported by other studies as those areas in which patients and caregivers request to receive more information. However, there is a lack of specialized learning recourses to cover these ongoing needs [35]. The provision of explanatory context and support from HCPs, as well as information consistency have been valued as factors that can increase patients satisfaction [52]. In the same direction, assistive technologies such as sensors to measure physiological signals can provide patients with reasoning and so, with better understanding of symptoms related to rehabilitation treatments [34]. The design of information provision in HNC patients is a highly complex process underpinned not only by the complexity of the disease itself, but also from the unique requirements and needs of each patient [12, 47, 59, 64]. Co-design of personalized information tools for newly diagnosed cancer patients has been seen to contribute to the creation of responsive rehabilitation technologies [28]. Meanwhile the projection of cancer towards becoming a chronic condition, brings sensing and context-aware computing to the spotlight, as these technologies can facilitate outpatient care contributing in the long-term to better quality of life [34]. Diagnosis of cancer is a stressful life event for patients and informal caregivers leading often to emotional, physical and social crisis [16].

Another endorsed problem related to information provision concerns information management. Both patients and informal caregivers argued that managing and having an overview of information has been challenging. Information management issues, such as the difficulty to keep track of all the treatments and interventions needed during rehabilitation has been attributed to the non-digital format of information and the lack of an efficient information management system. The patients faced difficulties in handling the amount of data they were receiving due to many appointments with different HCPs in various locations and times, or unorganized information on the available services and treatments. Previous research concluded that the journeys cancer patients undergo are often fragmented and highly individual, as each patient has different needs [30]. Personalization of services and patient involvement to the design process of interventions has been considered to be valuable to identify the variety of encounters within treatment and rehabilitation processes and to point out the moments that patients experience physical, psychological, and social difficulties [31, 47]. The positive effects of HCPs-patient communication on patients' health outcomes indicate that inclusion of patients in the design of this process can result in better health outcomes [67].

In the same vein, a holistic design of the services could also contribute towards re-allocation of organizational and structural responsibilities. Currently, in Denmark the responsibilities are allocated at various authorities on different governmental levels, with municipalities to hold the responsibility for the generalised rehabilitation interventions, while the hospitals for the specialized rehabilitation services for patients with cancer $[5,15,66]$. Rehabilitation responsibilities at various authorities and on different governmental levels reported as a factor that can cause dissatisfaction, confusion or lower the trust of patients, as the allocation of responsibilities and authority is not always transparent. The municipalities do not posse specialized proficiency needed to elaborate rehabilitation of $\mathrm{HNC}$ patients, due to differences in population size and therefore to number of cancer incidence [43]. Both knowledge and professional skills are divided across great distances, which often hinders closer collaboration across professional groups and united specialized knowledge. Better collaboration between hospitals and municipalities could offer a seamless experience for patients and to contribute towards establishing a trust relationship between the two parties [43].

Besides organizational and structural problems, the HCPs who are working on municipalities located outside the Danish capital, point out an unmet need for knowledge sharing between HCPs. While this practice is common on the secondary sector, HCPs stated that it is not common in the primary sector. They proposed that to peer-to-peer knowledge sharing could elicit essential and updated information regarding the complex needs of HNC patients. Knowledge generation practices through reflection on clinical experiences, or working relationships are sources of information that HCPs can benefit from, nevertheless under-utilization of sharing professional experiences is common practice in healthcare [41]. Inter-professional collaboration can result in more efficient communication between team members, but also better understanding of patients' needs [26]. In addition, HCPs argued that knowledge input from HNC patients pertinent to their rehabilitation experience or needs in general, could improve the service by amplifying the voice of patients. The positive effects of these peer-support practices have been reported not only for HCPs but also for HNC patients [56], and patients with other cancer types [36]. Sundhed.dk and CKSK are planning to create an information portal for patients with $\mathrm{HNC}$, which will facilitate patients, informal caregivers and HCPs during HNC rehabilitation.

Understanding the interrelated needs of HNC patients, informal caregivers and HCPs during the rehabilitation process, can facilitate the design of holistic pervasive computing solutions. A recent paper [39] proposing a cancer journey framework depicts the responsibilities, challenges, and personal impacts patients face while transitioning from diagnosis through post-treatment survivorship, emphasizing the need for a coordinated system of tools and resources that may provide holistic and flexible support for patients and other stakeholders to navigate their cancer journey. This study confirms several challenges that have been reported by previous research, while adds new knowledge pertinent to the interrelated needs of patients and stakeholders during HNC rehabilitation. The present study has several limitations. For instance, the data collection was not performed by the authors, while multiple different data collection processes were combined in order to collect the data. These issues might have contributed to a sampling bias. Also, the secondary synthesis of data gathered for another purpose might have impact on the quality of data. Therefore, the generalizability of the study is limited within the Danish context.

\section{ETHICS APPROVAL AND CONSENT TO PARTICIPATE}

The ethics committee of the IT-University of Copenhagen follows the principles of the Danish Code of Conduct for Research Integrity, which states that no formal ethical approval is required for the type of study presented here. The participants signed an informed consent form prior to the study, and were aware of their right to 
withdraw from the study at any time. The ethical procedure of the Center For Kraeft \& Sundhed Kobenhavn was followed.

\section{CONSENT FOR PUBLICATION}

Not applicable.

\section{ACKNOWLEDGEMENTS}

The authors would like to thank Center For Kraeft \& Sundhed Kobenhavn and Sundhed.dk for the collaboration with IT-University of Copenhagen, also the students of IT-University of Copenhagen who took part in data collection activities.

Author V.M. has received funding from the European Union's Horizon 2020 research and innovation programme - Marie SklodowskaCurie Actions Grant Agreement No. 676201 - CHESS - Connected Health Early Stage Researcher Support System.

\section{REFERENCES}

[1] 2004. Rehabilitation in Denmark: A White Paper about the concept of rehabilitation. (2004). [Accessed: February 2019].

[2] 2016. Patients Cancer Plan, [In Danish]. (2016). [Accessed: February 2019].

[3] 2018. Danish Breast Cancer Organization. (2018). [Accessed: February 2019].

[4] 2018. The Danish Cancer Society. (2018). [Accessed: February 2019].

[5] 2018. The Danish Health Authority. Cancer pathways. (2018). [Accessed: February 2019].

[6] 2018. Program for rehabilitation and palliation in connection with cancer [In Danish]. (2018). [Accessed: February 2019].

[7] 2018. World Health Organisation, Rehabilitation. (2018). [Accessed: February 2019].

[8] Allison J Applebaum, Carol J Farran, Allison M Marziliano, Anna R Pasternak, and William Breitbart. 2014. Preliminary study of themes of meaning and psychosocial service use among informal cancer caregivers. Palliative \& supportive care 12, 2 (2014), 139-148.

[9] Athanassios Argiris, Michalis V. Karamouzis, David Raben, and Robert L. Ferris 2008. Head and neck cancer.(Author abstract). The Lancet 371, 9625 (2008).

[10] Virginia Braun and Victoria Clarke. 2006. Using thematic analysis in psychology. Qualitative research in psychology 3, 2 (2006), 77-101.

[11] David M Brennan, Sue Mawson, and Simon Brownsell. 2009. Telerehabilitation enabling the remote delivery of healthcare, rehabilitation, and self management. Stud Health Technol Inform 145 (2009), 231-248.

[12] Sally Brockbank, Nicholas Miller, Sarah Owen, and Joanne M Patterson. 2015 Pretreatment information on dysphagia: exploring the views of head and neck cancer patients. Fournal of pain and symptom management 49, 1 (2015), 89-97.

[13] Eusebio Torres Carranza, Pedro Infante Cossío, José María Hernández Guisado Elena Hens Aumente, and JLG Perez. 2008. Assessment of quality of life in oral cancer. Med Oral Patol Oral Cir Bucal 13, 11 (2008), E735-741.

[14] Anil K Chaturvedi, William F Anderson, Joannie Lortet-Tieulent, Maria Paula Curado, Jacques Ferlay, Silvia Franceschi, Philip S Rosenberg, Freddie Bray, and Maura L Gillison. 2013. Worldwide trends in incidence rates for oral cavity and oropharyngeal cancers. Fournal of clinical oncology 31, 36 (2013), 4550.

[15] Terkel Christiansen. 2012. Ten years of structural reforms in Danish healthcare. Health policy 106, 2 (2012), 114-119.

[16] AM Cliff and RP MacDonagh. 2000. Psychosocial morbidity in prostate cancer: II. A comparison of patients and partners. BfU international 86, 7 (2000), 834-839.

[17] David M. Cognetti, Randal S. Weber, and Stephen Y. Lai. 2008. Head and neck cancer. Cancer 113, S7 (2008), 1911-1932.

[18] Anna Cox, Valerie Jenkins, Susan Catt, Carolyn Langridge, and Lesley Fallowfield. 2006. Information needs and experiences: an audit of UK cancer patients. European fournal of Oncology Nursing 10, 4 (2006), 263-272.

[19] Emilie A C Dronkers, Steven W Mes, Marjan H Wieringa, Marc P van Der Schroeff, and Robert J Baatenburg de Jong. 2015. Noncompliance to guidelines in head and neck cancer treatment; associated factors for both patient and physician. 15 (2015).

[20] V D'souza, E Blouin, A Zeitouni, K Muller, and PJ Allison. 2017. Multimedia information intervention and its benefits in partners of the head and neck cancer patients. European journal of cancer care 26, 4 (2017), e12440.

[21] Violet D'souza, Maiziel Serrao, Erin Watson, Elizabeth Blouin, Anthony Zeitouni, and Paul J Allison. 2018. Information service in head and neck cancer care - a qualitative study. Supportive Care in Cancer 26, 1 (2018), 91-98.
[22] Margaret Eades, Jessica Murphy, Siobhan Carney, Shafia Amdouni, Josée Lemoignan, Marta Jelowicki, Michelle Nadler, Martin Chasen, and Bruno Gagnon. 2013. Effect of an interdisciplinary rehabilitation program on quality of life in patients with head and neck cancer: review of clinical experience. Head \& neck 35, 3 (2013), 343-349.

[23] Mary Y Egan, Sara McEwen, Lindsey Sikora, Martin Chasen, Margaret Fitch, and Susan Eldred. 2013. Rehabilitation following cancer treatment. Disability and rehabilitation 35, 26 (2013), 2245-2258.

[24] Carolyn Y Fang and Carolyn J Heckman. 2016. Informational and support needs of patients with head and neck cancer: Current status and emerging issues. Cancers of the head \& neck 1, 1 (2016), 15.

[25] Christina Fitzmaurice, Christine Allen, Ryan M Barber, Lars Barregard, Zulfiqar A Bhutta, Hermann Brenner, Daniel J Dicker, Odgerel Chimed-Orchir, Rakhi Dandona, Lalit Dandona, et al. 2017. Global, regional, and national cancer incidence, mortality, years of life lost, years lived with disability, and disability-adjusted life-years for 32 cancer groups, 1990 to 2015: a systematic analysis for the global burden of disease study. JAMA oncology 3, 4 (2017), 524-548.

[26] Cynthia Foronda, Brent MacWilliams, and Erin McArthur. 2016. Interprofessional communication in healthcare: An integrative review. Nurse education in practice 19 (2016), 36-40.

[27] Gemma Gatta, Laura Botta, María José Sánchez, Lesley Ann Anderson, Daniela Pierannunzio, Lisa Licitra, M Hackl, N Zielonke, W Oberaigner, E Van Eycken, et al. 2015. Prognoses and improvement for head and neck cancers diagnosed in Europe in early 2000s: The EUROCARE-5 population-based study. European journal of cancer 51, 15 (2015), 2130-2143.

[28] Michael J Gonzales and Laurel D Riek. 2013. Co-designing patient-centered health communication tools for cancer care. In Proceedings of the 7th International Conference on Pervasive Computing Technologies for Healthcare. ICST (Institute for Computer Sciences, Social-Informatics and ?, 208-215.

[29] Roganie Govender, Christina H Smith, Benjamin Gardner, Helen Barratt, and Stuart A Taylor. 2017. Improving swallowing outcomes in patients with head and neck cancer using a theory-based pretreatment swallowing intervention package: protocol for a randomised feasibility study. BM7 open 7, 3 (2017), e014167.

[30] Maria Hägglund, Peter Bolin, and Sabine Koch. 2015. Living with Lung CancerPatients' Experiences as Input to eHealth Service Design.. In MedInfo. 391-395.

[31] Sigrídur Halldórsdóttir and Elisabeth Hamrin. 1997. Caring and uncaring encounters within nursing and health care from the cancer patient's perspective. Cancer nursing 20, 2 (1997), 120-128.

[32] David W Hamilton, Ben Heaven, Richard G Thomson, Janet A Wilson, and Catherine Exley. 2016. Multidisciplinary team decision-making in cancer and the absent patient: a qualitative study. BMF open 6, 7 (2016), e012559.

[33] Marja Harjumaa, Saila Saraniemi, Saara Pekkarinen, Minna Lappi, Heidi Similä, and Minna Isomursu. 2016. Feasibility of digital footprint data for health analytics and services: an explorative pilot study. BMC medical informatics and decision making 16, 1 (2016), 139.

[34] Gillian R Hayes, Gregory D Abowd, John S Davis, Marion L Blount, Maria Ebling, and Elizabeth D Mynatt. 2008. Opportunities for pervasive computing in chronic cancer care. In International Conference on Pervasive Computing. Springer, 262279.

[35] Tara Herrmann, Pamela M Peters, and Emily Sherene Van Laar. 2017. Online education needs and preferences of patients with cancer and their caregivers. (2017).

[36] Louisa M Hoey, Sandra C Ieropoli, Victoria M White, and Michael Jefford. 2008. Systematic review of peer-support programs for people with cancer. Patient education and counseling 70, 3 (2008), 315-337.

[37] Lise Vilstrup Holm, Dorte Gilså Hansen, Christoffer Johansen, Peter Vedsted, Pia Veldt Larsen, Jakob Kragstrup, and Jens Søndergaard. 2012. Participation in cancer rehabilitation and unmet needs: a population-based cohort study. Supportive Care in Cancer 20, 11 (2012), 2913-2924.

[38] Joe Jabbour, Chris Milross, Puma Sundaresan, Ardalan Ebrahimi, Heather L Shepherd, Haryana M Dhillon, Gary Morgan, Bruce Ashford, Muzib Abdul-Razak, Eva Wong, et al. 2017. Education and support needs in patients with head and neck cancer: A multi-institutional survey. Cancer 123, 11 (2017), 1949-1957.

[39] ML Jacobs, James Clawson, and Elizabeth D Mynatt. 2017. Articulating a PatientCentered Design Space for Cancer Journeys. EAI endorsed transactions on pervasive health and technology 3, 9 (2017).

[40] Jeffrey Kaye. 2017. Making pervasive computing technology pervasive for health \& wellness in aging. Public Policy \& Aging Report 27, 2 (2017), 53-61.

[41] Elizabeth Anne Kinsella. 2010. Professional knowledge and the epistemology of reflective practice. Nursing philosophy 11, 1 (2010), 3-14

[42] Tamar Kotz, Alex D Federman, Johnny Kao, Lyudmila Milman, Stuart Packer, Coral Lopez-Prieto, Kevin Forsythe, and Eric M Genden. 2012. Prophylactic swallowing exercises in patients with head and neck cancer undergoing chemoradiation: a randomized trial. Archives of Otolaryngology-Head \& Neck Surgery 138, 4 (2012), 376-382. 
[43] Maria Kristiansen, Lis Adamsen, Karin Piil, Ida Halvorsen, Nanna Nyholm, and Carsten Hendriksen. 2017. A three-year national follow-up study on the development of community-level cancer rehabilitation in Denmark. Scandinavian journal of public health (2017).

[44] Akira Kugaya, Tatsuo Akechi, Toru Okuyama, Tomohito Nakano, Ichiro Mikami, Hitoshi Okamura, and Yosuke Uchitomi. 2000. Prevalence, predictive factors, and screening for psychologic distress in patients with newly diagnosed head and neck cancer. Cancer 88, 12 (2000), 2817-2823.

[45] Steinar Kvale. 1996. The interview as a conversation. InterViews: An introduction to qualitative research interviewing (1996), 19-37.

[46] Steinar Kvale and Svend Brinkmann. 2009. Interview: introduktion til et håndværk. (2009).

[47] CD Llewellyn, M McGurk, and J Weinman. 2006. How satisfied are head and neck cancer (HNC) patients with the information they receive pre-treatment? Results from the satisfaction with cancer information profile (SCIP). Oral oncology 42, 7 (2006), 726-734

[48] Margaret L Longacre, John A Ridge, Barbara A Burtness, Thomas J Galloway, and Carolyn Y Fang. 2012. Psychological functioning of caregivers for head and neck cancer patients. Oral oncology 48, 1 (2012), 18-25.

[49] Sara McEwen, Ana Maria Rodriguez, Rosemary Martino, Ian Poon, Colleen Dunphy, Jorge Norman Rios, and Jolie Ringash. 2016. ?I didn?t actually know there was such a thing as rehab?: survivor, family, and clinician perceptions of rehabilitation following treatment for head and neck cancer. Supportive Care in Cancer 24, 4 (2016), 1449-1453.

[50] Sara E McEwen, Aileen M Davis, Jennifer M Jones, Rosemary Martino, Ian Poon, Ana Maria Rodriguez, and Jolie Ringash. 2015. Development and preliminary evaluation of a rehabilitation consult for survivors of head and neck cancer: an intervention mapping protocol. Implementation Science 10, 1 (2015), 6.

[51] Maurene McQuestion, Margaret Fitch, and Doris Howell. 2011. The changed meaning of food: Physical, social and emotional loss for patients having received radiation treatment for head and neck cancer. European fournal of Oncology Nursing 15, 2 (2011), 145-151.

[52] Moyra E Mills and Kate Sullivan. 1999. The importance of information giving for patients newly diagnosed with cancer: a review of the literature. Fournal of clinical nursing 8, 6 (1999), 631-642.

[53] V Morrison, BJ Henderson, F Zinovieff, G Davies, R Cartmell, A Hall, and S Gollins. 2012. Common, important, and unmet needs of cancer outpatients. European fournal of Oncology Nursing 16, 2 (2012), 115-123.

[54] Alexander Osterwalder, Yves Pigneur, Gregory Bernarda, and Alan Smith. 2014 Value proposition design: How to create products and services customers want. (2014).

[55] Jens Overgaard, Aleksandar Jovanovic, Christian Godballe, and Jesper Grau Eriksen. 2016. The Danish head and neck cancer database. Clinical epidemiology 8 (2016), 491

[56] KA Pateman, PJ Ford, MD Batstone, and CS Farah. 2015. Coping with an altered mouth and perceived supportive care needs following head and neck cancer treatment. Supportive Care in Cancer 23, 8 (2015), 2365-2373.

[57] Joanne M Patterson, Elaine McColl, Janet Wilson, Paul Carding, and Tim Rapley. 2015. Head and neck cancer patients' perceptions of swallowing following chemoradiotherapy. Supportive Care in Cancer 23, 12 (2015), 3531-3538.

[58] Kjeld Møller Pedersen, Terkel Christiansen, and Mickael Bech. 2005. The Danish health care system: evolution-not revolution-in a decentralized system. Health economics 14, S1 (2005), S41-S57.

[59] Kristian Pollock, Karen Cox, Penny Howard, Eleanor Wilson, and Nima Moghaddam. 2008. Service user experiences of information delivery after a diagnosis of cancer: a qualitative study. Supportive Care in Cancer 16, 8 (2008), 963-973.

[60] Valesca P Retèl, Lisette van der Molen, Frans JM Hilgers, Coen RN Rasch, Annemiek AAMHJ l'Ortye, Lotte MG Steuten, and Wim H van Harten. 2011. A cost-effectiveness analysis of a preventive exercise program for patients with advanced head and neck cancer treated with concomitant chemo-radiotherapy. BMC cancer 11, 1 (2011), 475 .

[61] Jolie Ringash, Lori J Bernstein, Gerald Devins, Colleen Dunphy, Meredith Giuliani, Rosemary Martino, and Sara McEwen. 2018. Head and neck cancer survivorship: learning the needs, meeting the needs. In Seminars in radiation oncology, Vol. 28 Elsevier, 64-74.

[62] Simon N Rogers, B Scott, D Lowe, G Ozakinci, and GM Humphris. 2010. Fear of recurrence following head and neck cancer in the outpatient clinic. European Archives of Oto-Rhino-Laryngology 267, 12 (2010), 1943-1949.

[63] Yevgeniy R Semenov, Heather M Starmer, and Christine G Gourin. 2012. The effect of pneumonia on short-term outcomes and cost of care after head and neck cancer surgery. The Laryngoscope 122, 9 (2012), 1994-2004.

[64] Cherith J Semple and BRIAN McGOWAN. 2002. Need for appropriate written information for patients, with particular reference to head and neck cancer. fournal of clinical nursing 11, 5 (2002), 585-593.

[65] Marc Stickdorn, Jakob Schneider, Kate Andrews, and Adam Lawrence. 2011. This is service design thinking: Basics, tools, cases. 1 (2011)
[66] Martin Strandberg-Larsen, Mikkel Bernt Nielsen, Allan Krasnik, and Karsten Vrangbæk. 2006. Is Denmark prepared to meet future health care demands? Eurohealth 12, 4 (2006), 7-10.

[67] Richard L Street Jr, Gregory Makoul, Neeraj K Arora, and Ronald M Epstein. 2009. How does communication heal? Pathways linking clinician-patient communication to health outcomes. Patient education and counseling 74, 3 (2009), 295-301.

[68] Sandra van Dulmen. 2011. The value of tailored communication for personcentred outcomes. Journal of Evaluation in Clinical Practice 17, 2 (2011), 381-383.

[69] Janet A Wilson, Paul N Carding, and Joanne M Patterson. 2011. Dysphagia after nonsurgical head and neck cancer treatment: patients' perspectives. Otolaryngology-head and neck surgery 145, 5 (2011), 767-771.

[70] Robert K Yin. 2017. Case study research and applications: Design and methods. Sage publications. $22-26$ pages. 